\title{
Adenosine Decreases Action Potential Duration by Modulation of A-Current in Rat Locus Coeruleus Neurons
}

\author{
Wilbur J. Pan, Smajo S. Osmanović, and Sarah A. Shefner \\ Department of Physiology and Biophysics, University of Illinois at Chicago, College of Medicine, Chicago, Illinois 60612
}

The possibility that adenosine modulates voltage-dependent conductances in locus coeruleus neurons was investigated in current-clamp and voltage-clamp experiments in a totally submerged rat brain slice preparation. Adenosine $(100 \mu \mathrm{M})$ reduced the duration of control action potentials and action potentials prolonged by $1 \mathrm{~mm}$ barium. Adenosine $(100 \mu \mathrm{M})$ also reduced the amplitude and slightly reduced the duration of TTX-resistant "calcium" action potentials. Action potential duration was also reduced by the adenosine receptor agonist 2-chloroadenosine in a concentration-dependent manner and the adenosine-induced reduction of action potential duration was blocked by the adenosine receptor antagonlst 8-(p-sulfophenyl)theophylline, indicating that this action of adenosine is mediated by an adenosine receptor. The adenosine-induced reduction of action potential duration persisted in the presence of externally applied tetraethylammonium ion ( $6 \mathrm{~mm}$ ) and cesium ( $3 \mathrm{mM}$ ). By contrast, adenosine did not reduce the duration of the action potential in the presence of $500 \mu \mathrm{M}$ 4-aminopyridine (4-AP). Furthermore, 4-AP (30 $\mu \mathrm{M})$ blocked the adenosine-induced reduction of action potential duration recorded in the presence of $1 \mathrm{~mm}$ barium. These data suggested that adenosine may be acting on the voltage-dependent, 4-AP-sensitive potassium current, $I_{A}$. Single-electrode voltage clamp was used to study $I_{A}$ directly. $I_{A}$ was activated by depolarizing voltage pulses from a hyperpolarized holding potential and was blocked by $1 \mathrm{~mm}$ 4-AP. Adenosine $(300 \mu \mathrm{M})$ enhanced $I_{A}$ by shifting the steady-state inactivation curve in the depolarizing direction. The mean shift of the curve at $80 \%$ inactivation was $4.6 \mathrm{mV}$, which increases the amount of $I_{\mathrm{A}}$ available for activation at the threshold potential by 2.5 -fold. The same concentration of 4-AP $(30 \mu \mathrm{M})$ that blocked the adenosine-induced reduction in spike duration, completely blocked $I_{A}$ evoked from threshold potential. These data suggest that adenosine reduces action potential duration of locus coeruleus neurons through enhancement of $I_{A}$.

[Key words: adenosine, A-current, $I_{A}$, potassium channels, action potential, locus coeruleus]

\footnotetext{
Received Jan. 25, 1993; revised Aug. 6, 1993; accepted Aug. 9, 1993.

Grant support was provided by U.S. Public Health Service AA05846 to S.A.S. We thank Dr. R. D. Wirtshafter for his help regarding statistical analysis and Dr. S. Nakajima for helpful comments on the manuscript.

Correspondence should be addressed to Dr. Sarah A. Shefner, Department of Physiology and Biophysics (M/C 901), University of Illinois at Chicago, College of Medicine, 901 South Wolcott Avenue, Room E-202 MSB, Chicago, IL 606127342.

Copyright (C) 1994 Society for Neuroscience $0270-6474 / 94 / 141114-09 \$ 05.00 / 0$
}

Adenosine has been shown to have many effects on the CNS, including sedation, anticonvulsant action, protection against ischemia, and regulation of blood flow in the cerebral vasculature (for reviews, see Dunwiddie, 1985; Greene and Haas, 1991). It is possible that some of these effects could be mediated by actions of adcnosinc on the locus cocrulcus (LC). The LC is the largest noradrenergic nucleus in the CNS, and is involved in arousal, sleep, selective attention, and innervation of the cerebral vasculature (Foote et al., 1983). Adenosine has been shown to modulate the activity of noradrenergic neurons. For example, adenosine inhibits norepinephrine release in the sympathetic nervous system (Fredholm, 1976; Verhaeghe et al., 1976; Clanachan et al., 1977). In the CNS, adenosine analogs have been found to inhibit norepinephrine release in hippocampal slices (Dunwiddie et al., 1986), in neocortex slices (Harms et al., 1978), and from brain vesicular preparations (Ebstein and Daly, 1982). Methylxanthines increase norepinephrine turnover in the brain (Waldeck, 1971) and increase the rate of firing in the LC, perhaps through blockade of tonic purinergic inhibition (Olpe et al., 1983). Our laboratory has shown that adenosine reduces the spontaneous firing rate of $\mathrm{LC}$ neurons in a brain slice preparation and this effect is often associated with a membrane hyperpolarization due to a steady-state outward current (Shefner and Chiu, 1986; Pan et al., 1988). The possibility that adenosine might also modulate voltage-dependent conductances was investigated by examining the effects of adenosine on the shape of the action potential. This report demonstrates an action of adenosine on a transient outward current $\left(I_{\mathrm{A}}\right)$ in LC neurons that leads to a reduction of action potential duration. This is the first direct evidence for an action of adenosine on a voltage-activated potassium current and explains an earlier observation in the literature that some of the effects of adenosine on central neurons could be reversed by the potassium channel blocker 4-aminopyridine (4-AP; Okada and Ozawa, 1980; Perkins and Stone, 1980; Schubert and Lee, 1986; Scholfield and Steel, 1988).

A portion of the data in this paper has been previously reported in abstract form (Pan and Shefner, 1992).

\section{Materials and Methods}

Male Fischer 344 rats (125-200 gm) were used. The rats were killed by cervical dislocation and the brain was rapidly dissected out. A block of tissue containing the pons was glued onto a Plexiglas stage next to an agar block for support during sectioning. The tissue block was submerged in an oxygenated bath of artificial cerebrospinal fluid (aCSF) at $4-6^{\circ} \mathrm{C}$ in the well of a Lancer 1000 vibratome. Coronal slices $(300 \mu \mathrm{m})$ were then cut. In these sections, the LC can be recognized as a dark gray nucleus on the lateral border of the central gray. A slice containing the caudal portion of the $L C$ is preferred in this preparation, as this portion of the LC contains the highest density of noradrenergic cell 


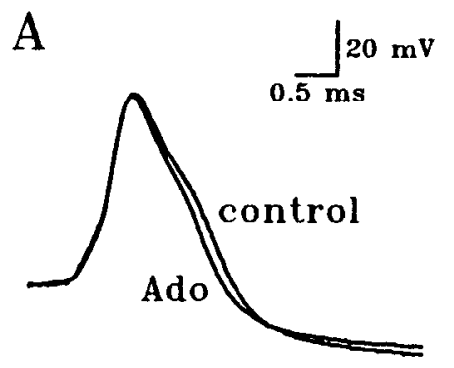

$\mathrm{D}$

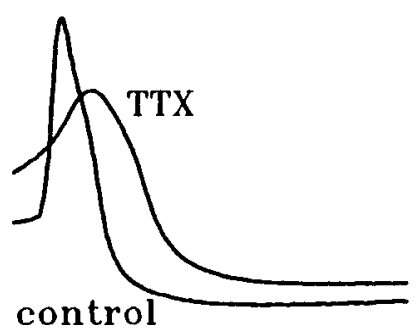

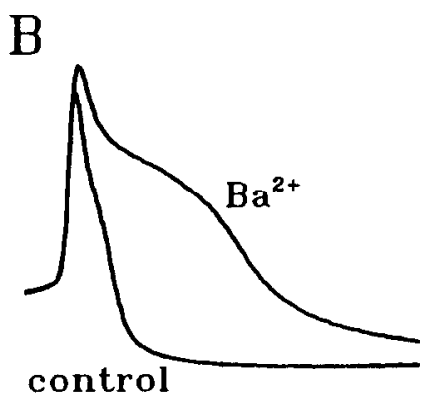

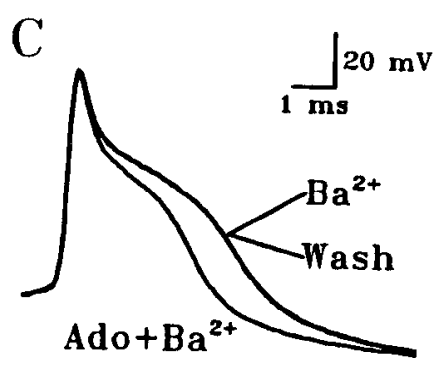

Figure 1. Effect of adenosine on action potential shape in a typical LC neuron. $A$, Adenosine $(100 \mu \mathrm{M})$ caused a small but consistent decrease in the duration of the action potential recorded in control aCSF. Adenosine also caused a consistent decrease in the peak afterhypcrpolarization following the action potential. $B$, Bath application of barium $(1 \mathrm{~mm})$ prolonged the duration of the action potential. $C$, Adenosine (100 $\mu \mathrm{M})$ shortened the duration of the barium action potential measured at one-third the peak amplitude by $29 \%$. These effects reversed upon washout. $A-C$ are from the same cell. The resting membrane potential (RMP) of the cell was $-57 \mathrm{mV}$ and was unchanged by adenosine. $D$, In a separate LC neuron, administration of TTX $(1 \mu \mathrm{M})$ raised the threshold, decreased the peak amplitude, increased the duration, and slowed the rate of rise of the action potential. $E$, Adenosine reduced both the amplitude and the duration of this TTX-resistant "calcium" action potential. These effects reversed upon washout. $D$ and $E$ are from the same cell. RMP of this cell was $-60 \mathrm{mV}$. TTX raised threshold by $+11 \mathrm{mV}$. All action potential waveforms in this and the following figures are computer averages of 10 action potentials.

bodies. The recording chamber consisted of a small Plexiglas reservoir with a volume of approximately $0.3 \mathrm{ml}$. The slice was placed upon a small piece of lens paper that rested on a tightly stretched nylon net. Two electron microscopy grids were placed on the slice, and platinum wire weights were placed on the grids to keep the slice from floating. The composition of aCSF was as follows: $126 \mathrm{~mm} \mathrm{NaCl}, 2.5 \mathrm{~mm} \mathrm{KCl}$, $1.3 \mathrm{~mm} \mathrm{MgSO}_{4}, 2.4 \mathrm{mM} \mathrm{CaCl}_{2}, 25 \mathrm{~mm} \mathrm{NaHCO}, 1.2 \mathrm{~mm} \mathrm{NaH} \mathrm{PO}_{4}$, and $11 \mathrm{~mm}$ glucose. When saturated with $95 \% \mathrm{O}_{2}$ and $5 \% \mathrm{CO}_{2}$ at $36^{\circ} \mathrm{C}$, the $\mathrm{pH}$ of the aCSF was 7.4. The aCSF entered the bottom of the chamber by gravity flow, flowed out of the chamber at the top, and was removed by gravity suction. The temperature of the aCSF was 35.5$36.5^{\circ} \mathrm{C}$ and the flow rate was $2.2 \mathrm{ml} / \mathrm{min}$. The LC was clearly visible under the microscope when illuminated with transmitted light; under these viewing conditions, the LC appeared as a homogencous translucent area. The slice was mounted in the recording chamber and was allowed to equilibrate for $1 \mathrm{hr}$.

Electrodes were pulled from glass micropipettes $(1.0 \mathrm{~mm} \mathrm{OD})$ with a Brown-Flaming micropipette puller. The electrodes were filled with $2 \mathrm{M} \mathrm{KCl}$, and had resistances of $60-100 \mathrm{M} \Omega$. The electrode was positioned in the LC under visual control. Intracellular recordings were obtained in current clamp mode on an Axoclamp 2A amplifier. Cells were impaled by quickly oscillating the capacity compensation unit of the amplifier. Capacitive transients were minimized by adjusting the negative capacity compensation before impalement. The bridge was balanced before impalement and checked and readjusted as necessary during each experiment. Current and voltage were recorded both on a storage oscilloscope and with a rectilinear pen recorder. Spontaneous action potentials were captured and stored on videotape with an Instrutech VR-10 analog-to-digital converter for later off-line analysis. An IBM XT-compatible computer was used for averaging action potentials with either pCLAMP software (Axon Instruments) with a Labmaster DMA interface, or with software kindly provided by Dr. Thomas Dunwiddie (University of Colorado Med. Ctr., Denver, CO) using an RC Electronics Computerscope analog-to-digital converter. All action potential waveforms shown are averages of 10 action potentials.
Voltage-clamp experiments were performed in the discontinuous single-electrode voltage-clamp mode on an Axoclamp 2A amplifier with a sampling rate of $3.5-4.0 \mathrm{kHz}$. The headstage voltage was continuously monitored to ensure that full decay of the voltage transient occurred before the voltage recording cycle. Capacity compensation was monitored continuously and optimized during all voltage-clamp experiments. pCLAMP software was used to run voltage-clamp protocols and for computerized data acquisition and storagc. During voltagc-clamp expcriments, cells were held near resting membrane potential. All current traces from experiments in this report are averages of eight trials.

Drugs were dissolved in oxygenated aCSF and administered in the bath. Drug solutions were prepared fresh daily. The superfusion solution was switched to the drug-containing solution by means of a valve system. The short length of the inflow tubes allowed the drug to reach the recording chamber in $30 \mathrm{sec}$. The small size of the recording chamber ensured equilibration to a full steady-state concentration in about 2 min. With this system, known concentrations of the drug can be applied.

All average values in the text are reported as mean \pm SEM. Action potential duration was measured at $33 \%$ of the peak amplitude in order to measure adenosine-induced changes at the widest portion of the action potential. Effects of adenosine upon the inactivation characteristics of $I_{\mathrm{A}}$ were analyzed with a multivariate analysis of variance (MANOVA) and the statistical significance of the univariate $F$ values determined according to the Bonferroni correction (Miller, 1981).

\section{Results}

Stable intracellular recordings were obtained from $42 \mathrm{LC}$ neurons. All neurons exhibited typical electrophysiological properties of LC neurons (Williams et al., 1984), that is, resting membrane potentials of -55 to $-65 \mathrm{mV}$, apparent resting input resistances of 150-300 $\mathrm{M} \Omega$, and overshooting action potentials of 70-80 $\mathrm{mV}$ in amplitude. All neurons fired spontaneously at rates of $0.5-3.0 \mathrm{~Hz}$. All the following measurements of aden- 
A
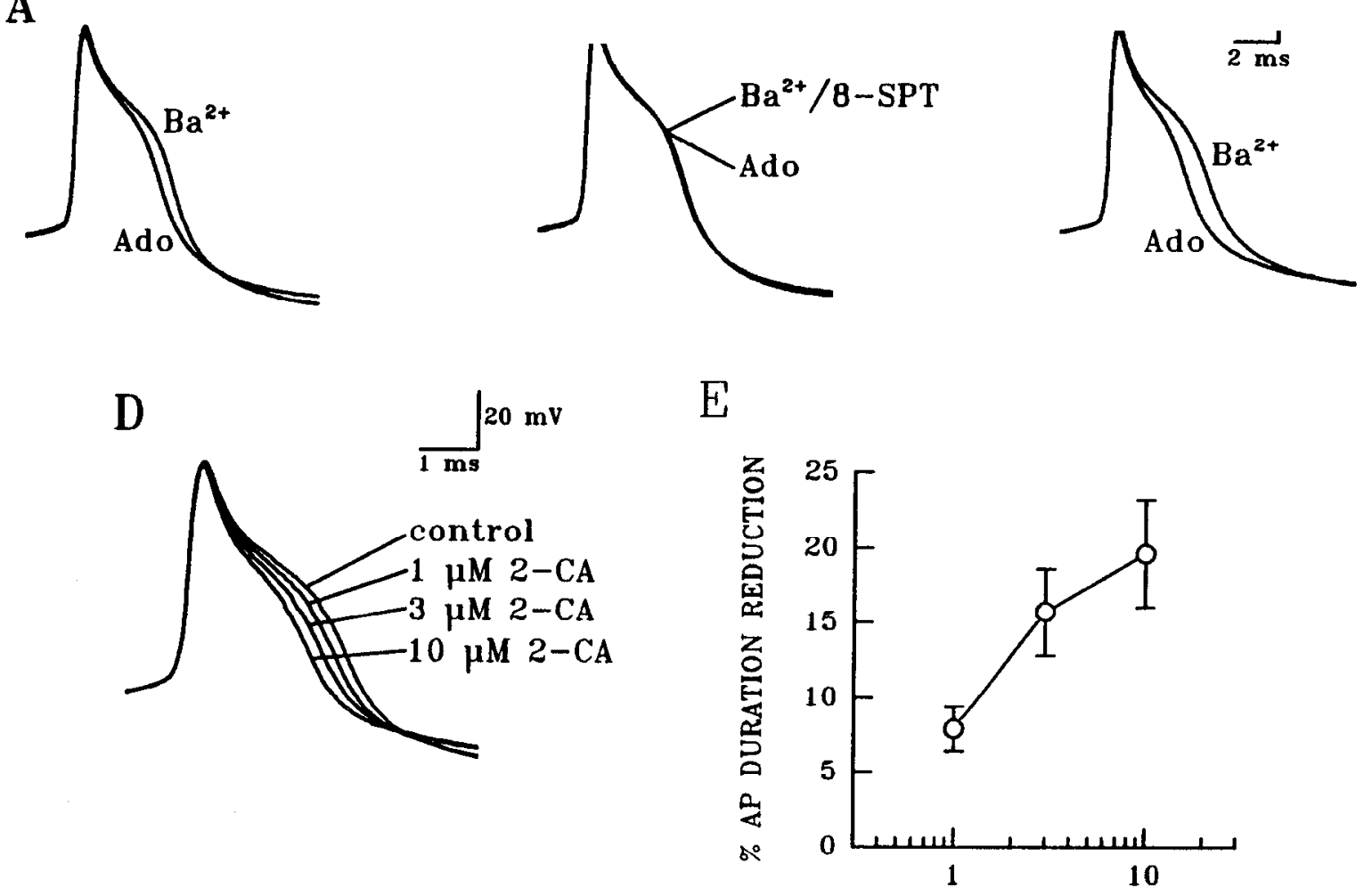

2-CHLOROADENOSINE (uM)

Figure 2. Receptor mediation of the adenosine effect. $A$, Adenosine $(100 \mu \mathrm{M})$ reduced the duration of the barium action potential measured at one-third the peak amplitude by $15 \%$. $B$, When adenosine was reapplied in the presence of the adenosine receptor antagonist 8 - $(p$-sulfophenyl)theophylline $(8-S P T ; 200 \mu \mathrm{M})$, the effect of adenosine on the barium action potential was blocked. $C$, After washout of 8 -SPT, adenosine was again able to reduce the duration of the barium action potential. RMP of the cell was $-65 \mathrm{mV}$. $D$, In a different LC neuron, the adenosine analog 2 -chloroadenosine $(2-C A)$ decreased the duration of the barium action potential. Increasing concentrations of 2-CA caused successively larger reductions in action potential duration. RMP of the cell was $-63 \mathrm{mV}$. $E$, Graph of percentage reduction of action potential duration as a function of $\log$ concentration of 2-CA demonstrating the concentration dependence of this action of adenosine. Values are means \pm SEM from pooled data $(n=5$ cells at each point $)$.

osine effects on LC action potential shape were performed on spontancous action potentials.

\section{Adenosine reduces action potential duration}

Adenosine (100-300 $\mu \mathrm{M}$ ) was applied in the bath to six LC neurons in control aCSF and caused a slight but noticeable decrease in the duration of spontaneous action potentials in all cells tested (see Fig. $1 A$ ) Since this was a quantitatively small effect, barium ( $1 \mathrm{~mm}$ ) was added to the bath solution to prolong the duration of the action potential (Fig. $1 B$ ). Barium increases action potential duration by increasing inward current through calcium channels (Bean, 1989) and by blocking a number of potassium conductances, including the delayed rectifier and $I_{\mathrm{C}}$ (Rudy, 1988). It should be noted that barium blocks the adenosine-induced steady-state outward current (W. J. Pan, unpublished observation), and therefore adenosine did not hyperpolarize LC neurons in the presence of barium. Figure $1 C$ illustrates that adenosine reduced the duration of the spontaneous action potential in the presence of barium. The mean reduction by adenosine $(100 \mu \mathrm{M})$ of the duration of the barium action potential measured at one-third of the peak amplitude was $12.2 \pm 2.2 \%(n=13)$. Adenosine-induced shortening of the barium action potential reversed upon washout of adenosine.

The effect of adenosine was also tested in the presence of
TTX, which blocks voltage-dependent sodium channels. As previously shown, spontancous action potentials in LC neurons still occur in the presence of TTX, with calcium acting as the carrier of inward current (Williams et al., 1984). These "calcium" action potentials have a higher threshold, decreased amplitude, increased duration, and a slower rate of rise than control action potentials (Fig. 1D). In all four cells tested, adenosine $(100 \mu \mathrm{M})$ reduced the amplitude and slightly reduced the duration of spontaneous calcium action potentials (Fig. $1 E$ ). These effects of adenosine on calcium action potentials reversed upon washout.

In order to determine whether the adenosine-induced shortening of the action potential was mediated by adenosine receptors, 8 -( $p$-sulfophenyl)theophylline $(8-\mathrm{SPT} ; 200 \mu \mathrm{M})$ was administered to block adenosine receptors. 8-SPT has a $K_{i}$ of 2.6 $\mu \mathrm{M}$ against $\mathrm{A}_{1}$ receptors and a $K_{i}$ of $15.3 \mu \mathrm{M}$ against $\mathrm{A}_{2}$ receptors (Bruns et al., 1986). We chose this competitive antagonist because it is highly water soluble and more potent than theophylline, but shows no indication of phosphodiesterase inhibition in concentrations up to $1 \mathrm{~mm}$ (Gustafsson, 1984). Figure $2 A$ illustrates the reduction of barium action potential duration by $100 \mu \mathrm{M}$ adenosine in a typical LC neuron. The application of 8-SPT alone did not change the shape of the barium action potential, but antagonized the adenosine effect (Fig. 2B). After 
A

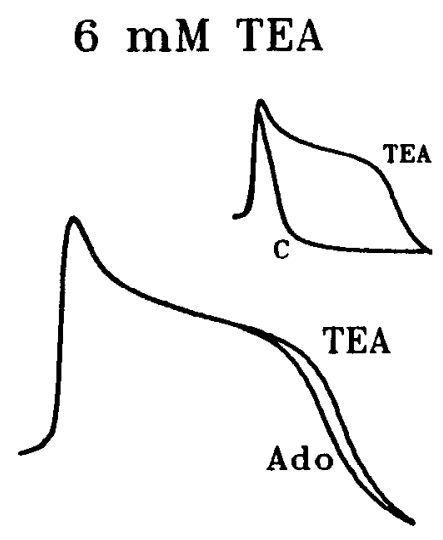

B $\quad 3 \mathrm{mM} \mathrm{Cs}^{+}$

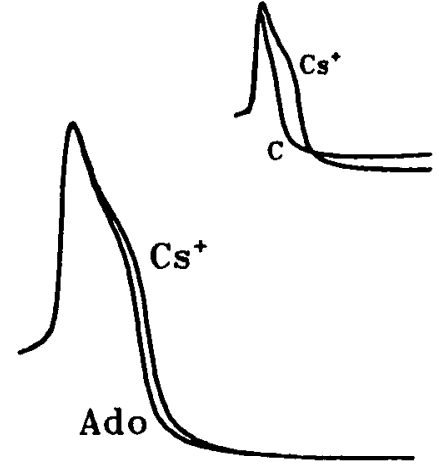

$\mathrm{C}$

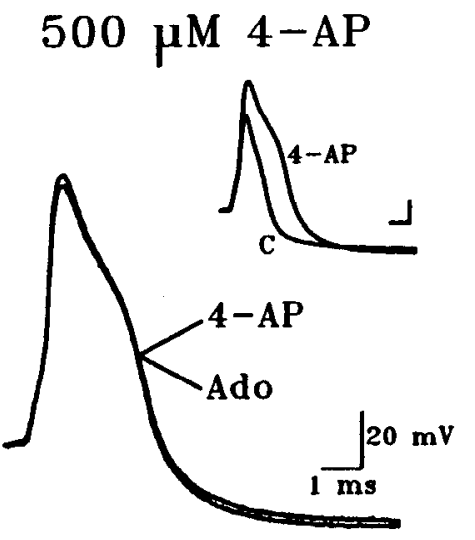

Figure 3. Effect of adenosine on LC action potentials in the presence of potassium channel blockers other than barium. $A$, When the action potential was prolonged by TEA $(6 \mathrm{mM})$ (inset), adenosine $(100 \mu \mathrm{M})$ reduced the duration of the action potential in this cell by $8 \%$. RMP of this cell was $-57 \mathrm{mV}$. $B$, When the action potential was broadened by $3 \mathrm{~mm}$ external cesium (inset), adenosine ( $100 \mu \mathrm{M}$ ) shortened the duration of the action potential in this cell by $16 \%$. RMP of this cell was $-59 \mathrm{mV}$. $C, 4$-Aminopyridine $(4-A P ; 500 \mu \mathrm{M})$ increased the duration and amplitude of the action potential (inset). Adenosine $(300 \mu \mathrm{M})$ failed to alter the shape of the action potential in the presence of 4-AP. RMP of this cell was -60 $\mathrm{mV}$.

washout of 8-SPT, $100 \mu \mathrm{M}$ adenosine once again reduced the duration of the barium action potential (Fig. $2 C$ ). In all five neurons tested, adenosine $(100 \mu \mathrm{M})$ reduced the duration of the barium action potential by an average of $10.6 \pm 0.7 \%$ and 8 -SPT $(200 \mu \mathrm{M})$ completely blocked the effect of adenosine.

The concentration dependence of the adenosine-induced reduction of action potential duration was investigated using the adenosine receptor agonist 2-chloroadenosine (2-CA), which is a more potent agonist at adenosine receptors than adenosine itself (Bruns et al., 1986) and is not a substrate for adenosine reuptake (Sturgill et al., 1975). Figure 2D shows that action potential duration progressively decreases with increasing concentrations of 2-CA. The mean percentage reduction in action potential duration was plotted as a function of $\log$ concentration of 2-CA from pooled data for $10 \mathrm{LC}$ neurons; all cells were not tested with each concentration ( $n=5$ per data point; Fig. $2 E$ ). These data clearly indicate the concentration dependence of the effect on action potential duration.

\section{Adenosine effects in the presence of tetraethylammonium ion and cesium}

To determine the mechanism by which adenosine reduces action potential duration, the effects of adenosine on action potential shape in the presence of potassium channel blockers other than barium were examined. Externally applied tetraethylammonium (TEA) blocks $I_{C}$ at $1 \mathrm{~mm}$ or less, delayed rectifiers at millimolar concentrations, and inward rectifiers in some cell types (Rudy, 1988). TEA (6 mM) prolonged the duration of spontaneous action potentials in LC neurons (Fig. $3 A$, inset). Figure $3 A$ shows that in the presence of $6 \mathrm{~mm}$ TEA, the adenosineinduced decrease in action potential duration could still be observed. On the avcrage, adcnosinc $(100 \mu \mathrm{m})$ shortened the duration of the $\mathrm{LC}$ action potential in the presence of TEA by 5.5 $\pm 0.6 \%(n=3)$. While adenosine decreased the duration of action potentials recorded both in TEA and in barium, the adenosine-induced change in action potential shape appeared to differ somewhat in these two conditions, in that adenosine typically reduced an earlier portion of the action potential and caused a greater reduction in duration in barium than in TEA (compare Figs. $1 C, 3 A$ ). Further studies into the conductances involved in action potential repolarization in LC neurons will be required to understand this difference. Spontaneous action potentials were also broadened by external cesium ( $3 \mathrm{~mm}$ ) (Fig. $3 B$, inset), which blocks the delayed rectifier and inward rectifier (Rudy, 1988). Adenosine decreased the duration of the cesium action potential, as illustrated in Figure $3 B$. In three cells tested, adenosine $(100 \mu \mathrm{M})$ caused a mean decrease in the duration of the cesium action potential of $8.6 \pm 1.5 \%$. The effects of adenosine on the shape of the action potentials in the presence of these channel blockers reversed upon washout.

\section{Adenosine effects in the presence of 4-aminopyridine}

While the adenosine-induced decrease in action potential duration persisted in the presence of the potassium channel blockers barium, cesium, and TEA, it was blocked in the presence of 4-AP. 4-AP has been shown to block $I_{\mathrm{A}}$ and delayed rectifiers (Rudy, 1988). In experiments in which the 4-AP antagonism of the adenosine effect was studied, the concentration of adenosine was increased to $300 \mu \mathrm{M}$ to maximize the adenosine-induced narrowing of action potential duration so that antagonism of this effect by 4-AP could be more accurately assessed. Adenosine $(300 \mu \mathrm{M})$ caused no reduction in action potential duration in all five cells tested in the presence of $500 \mu \mathrm{M} \mathrm{4-AP} \mathrm{(Fig.} \mathrm{3C).} \mathrm{In}$ addition to preventing the adenosine-induced shortening of action potential duration, 4-AP $(500 \mu \mathrm{M})$ increased the amplitude and prolonged the duration of spontaneous action potentials (Fig. 3C, inset) but did not change the resting membrane potential. Prominent spontaneous synaptic potential activity was seen in the presence of 4-AP. In order to better quantitate 4-AP antagonism of the adenosine-induced reduction of action potential duration, barium and 4-AP were applied simultaneously to LC neurons. A lower concentration of 4-AP $(30 \mu \mathrm{M})$ was used in these experiments because administration of higher concentrations of 4-AP in the presence of barium resulted in highly erratic firing and action potentials that varied greatly in duration and shape. Figure $4 A$ illustrates the adenosine-induced shortening of barium action potential duration in a typical LC neuron. In five cells tested, adenosine $(300 \mu \mathrm{M})$ shortened the duration of the action potential in the presence of $1 \mathrm{~mm}$ barium by 12.0 $\pm 4.4 \%$. In these same cells, application of $4-\mathrm{AP}(30 \mu \mathrm{M})$ with 

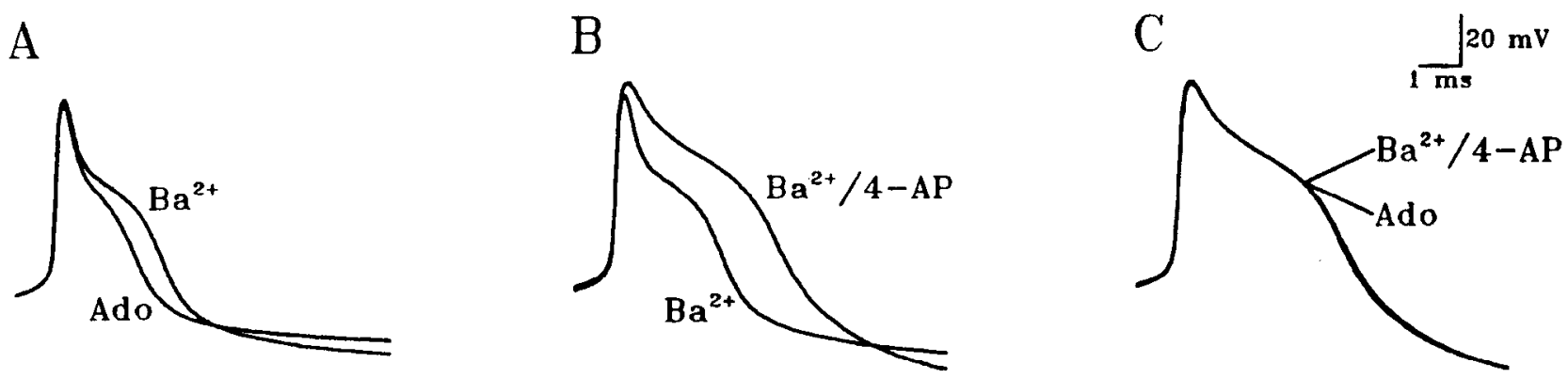

Figure 4. 4-AP blocks the adenosine-induced reduction in the duration of the barium action potential. $A$, In the presence of barium ( 1 mm), adenosine $(300 \mu \mathrm{M})$ reduced the duration of the action potential by $29 \%$ in this LC neuron. $B$, Addition of 4 -AP (30 $\mu \mathrm{M})$ in the presence of barium further prolonged the duration of the action potential. $C, 4-\mathrm{AP}(30 \mu \mathrm{M})$ blocked the reduction in the duration of the barium action potential induced by $300 \mu \mathrm{M}$ adenosine. All action potentials in this figure were obtained from the same cell. RMP of this cell was $-57 \mathrm{mV}$.

barium ( $1 \mathrm{~mm}$ ) further increased the duration of the action potential (Fig. 4B). Subsequent reapplication of adenosine in these same cells resulted in absolutely no decrease in the duration of the greatly prolonged action potential in 4-AP and barium in any of the five cells tested (see Fig. $4 C$ ).

\section{Effects of adenosine on $\mathbf{I}_{A}$}

The data shown above indicate that the ionic conductance that mediates the adenosine-induced reduction of action potential duration is blocked by 4-AP. The only ionic conductance known to contribute to the repolarization of the action potential that is not blocked by barium, TEA, or cesium, and is blocked by 4-AP, is $I_{\mathrm{A}}$ (Rudy, 1988). The experiments described above suggest that the adenosine-induced reduction of action potential duration could be due to an enhancement of $I_{\mathrm{A}}$. To test this hypothesis, the effect of adenosine on $I_{\mathrm{A}}$ was tested directly in voltage-clamp experiments. Inward currents were blocked by 0.5-1.0 $\mu \mathrm{M}$ TTX and $20 \mathrm{~mm} \mathrm{Mg}^{2+}$. These conditions have been shown to reduce inward currents greatly, as indicated by the absence of action potentials and calcium-activated afterhyperpolarizations (Osmanović and Shefner, 1993). A standard activation protocol for $I_{\mathrm{A}}$ was used in which cells were held near the resting membrane potential, and then given a $1 \mathrm{sec}$ conditioning pulse to $-95 \mathrm{mV}$, followed by a $200 \mathrm{msec}$ test pulse to potentials ranging from -55 to $-10 \mathrm{mV}$. Figure $5 A$ (part a) shows a transient outward current whose magnitude increased with the magnitude of the test pulse. This transient outward current decayed as a single exponential with a time constant of 30-40 msec. A concentration of $1 \mathrm{~mm} \mathrm{4-AP}$ was required to block this current completely (Fig. 5A, part b). The magnitude of the transient current was taken as the difference between the peak current and the steady-state current at the end of the test pulse. The transient outward current was plotted as a function of the membrane potential attained during the test pulse (Fig. $5 A$, part c). In four cells tested, on average, $50 \%$ activation of the transient outward current occurred at a potential of -36.8 $\pm 0.5 \mathrm{mV}$. The steady-state inactivation properties of the transient outward current were studied with the voltage protocol shown in Figure $5 B$ (part a, inset). In this steady-state inactivation protocol, cells were held near resting membrane potential $(-58$ to $-60 \mathrm{mV})$ and given $1 \mathrm{sec}$ conditioning pulses ranging from -80 to $-45 \mathrm{mV}$ followed by a $200 \mathrm{msec}$ test pulse to -15 $\mathrm{mV}$. Figure $5 B$ (part a) shows that the magnitude of the transient outward current decreased with less negative conditioning pulses and completely disappeared with a conditioning pulse of -45 $\mathrm{mV}$. The current evoked with this protocol was also blocked with $1 \mathrm{~mm}$ 4-AP (Fig. $5 B$, part b). Figure $5 B$ (part c) shows the plot of transient outward current amplitude as a function of conditioning pulse potential. The data from the activation and steady-state inactivation protocols were very well fit with a Boltzmann equation of the form

$$
I=\frac{I_{\max }}{1+e^{\left(i-r_{1}\right) / K}}
$$

where $I_{\max }$ is the maximum current, $V_{h}$ is the potential at which $50 \%$ inactivation occurs, and $K$ is the slope factor. As shown in Figure $5 B$ (part $c$, open circles), little inactivation occurs at potentials more negative than $-65 \mathrm{mV}$ with steep inactivation at more depolarized potentials. In five cells tested, $50 \%$ inactivation of the transient outward current was seen at a mean conditioning pulse potential of $-60.4 \pm 1.2 \mathrm{mV}$, and $80 \%$ inactivation of this current was seen at a mean conditioning pulse holding potential of $-56.1 \pm 1.1 \mathrm{mV}$, which is very near the threshold for LC neurons. These properties of the transient outward current as well as its block by $1 \mathrm{~mm} 4$-AP place it in the family of currents referred to as $I_{\mathrm{A}}$ (Rudy, 1988).

Adenosine modulation of $I_{\mathrm{A}}$ was investigated with the activation and steady-state inactivation protocols described above. In four cells tested with the activation protocol as shown in Figure $5 A$ (part a, inset), neither the amplitude nor the time course of decay of $I_{\mathrm{A}}$ was affected by $300 \mu \mathrm{M}$ adenosine (data not shown). Furthermore, activation curves for $I_{\mathrm{A}}$ were unchanged by the addition of adenosine as can be seen from the mean values of the parameters describing the activation curves for these four cells under control conditions $\left(I_{\max }=0.26 \pm 0.03\right.$ $\mathrm{nA}, V_{h}=-36.8 \pm 0.5 \mathrm{mV}$, and $\left.K=9.3 \pm 2.3\right)$ and in the presence of $300 \mu \mathrm{M}$ adenosine $\left(I_{\max }=0.25 \pm 0.02 \mathrm{nA}, V_{h}=\right.$ $-38.1 \pm 1.0 \mathrm{mV}$, and $K 9.0 \pm 2.1$ ).

In contrast, $300 \mu \mathrm{M}$ adenosine altered the voltage dependence of $I_{\mathrm{A}}$ when evoked with the steady-state inactivation protocol. Figure $6 A$ shows the family of A-currents elicited by the steadystate inactivation protocol in control aCSF. Note that the conditioning pulses of -45 to $-53 \mathrm{mV}$ caused nearly complete inactivation of $I_{\mathrm{A}}$ in control aCSF, but not in the presence of $300 \mu \mathrm{M}$ adenosine (compare the lower three current traces in Fig. $6 A, B)$. To illustrate this effect further, Figure $6 C$ shows an overlay of $I_{\mathrm{A}}$ currents in control aCSF, $300 \mu \mathrm{M}$ adenosine, and $30 \mu \mathrm{M} 4$-AP elicited from a conditioning pulse potential of -58 $\mathrm{mV}$. This potential is very close to the threshold for spontaneous action potential generation in LC neurons. The adenosine-induced enhancement of $I_{\mathrm{A}}$ evoked from this conditioning pulse 
A

a

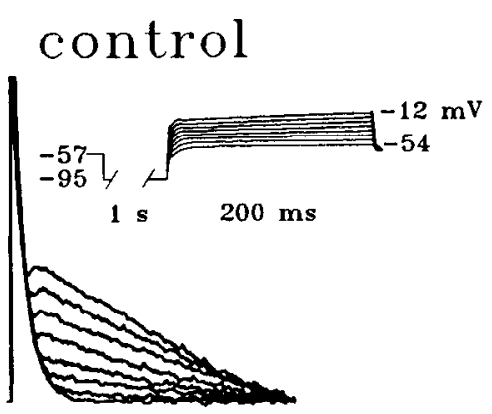

b

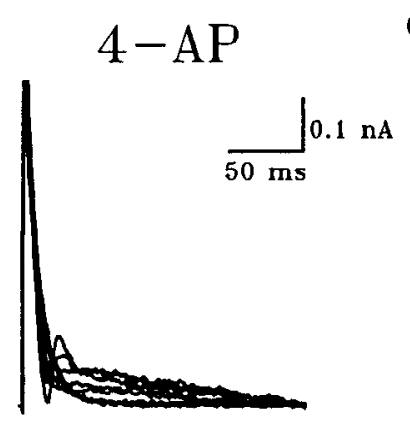

C

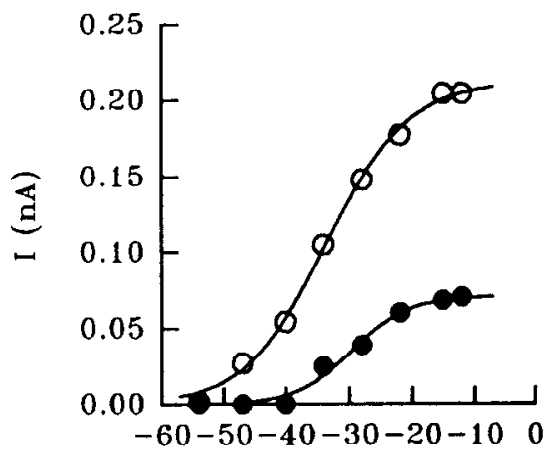

TEST POTENTIAL (mV)

B

a

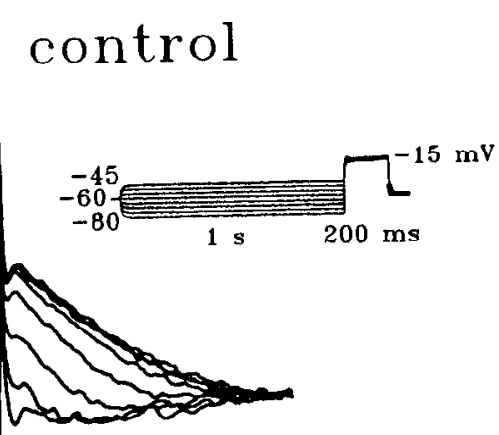

$\mathrm{b}$

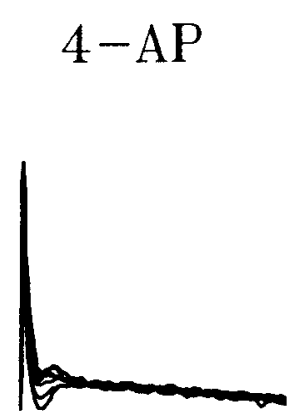

c

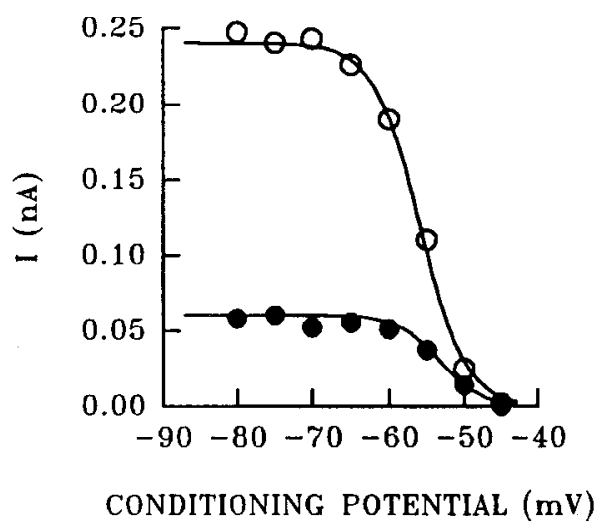

Figure 5. $I_{\mathrm{A}}$ in LC neurons and block by 4-AP. TTX $(0.5-1 \mu \mathrm{M})$ and $\mathrm{Mg}^{2+}(20 \mathrm{mM})$ were administered to LC neurons to block inward currents. $A, I_{\mathrm{A}}$ activation. Holding potential was $-57 \mathrm{mV}$. a, A family of A-currents was elicited using the activation protocol shown in the inset. Note that a conditioning pulse of $-95 \mathrm{mV}$ was used and that larger depolarizations evoked A-currents with larger amplitudes. $b$, After application of 1 mm 4-AP, the activation protocol evoked almost no A-current. $c$, Plot of peak A-current versus test pulse potential. The magnitude of the transient current was taken as the difference between the peak current and the steady-state current at the end of the test pulse. $O$, control aCSF; 1 mM 4-AP. Note that $I_{\mathrm{A}}$ was $50 \%$ activated at $-35 \mathrm{mV}$ and the reduction in $I_{\mathrm{A}}$ amplitude by 4-AP throughout the voltage range. $B, I_{\mathrm{A}}$ inactivation. Holding potential was $-60 \mathrm{mV}, a$, A family of A-currents was elicited using the inactivation protocol shown in the inset. Note that more depolarized conditioning pulses evoked A-currents with smaller amplitudes. $b$, After application of $1 \mathrm{mM} 4$-AP, the inactivation protocol evoked almost no A-current. $c$, Plot of peak A-current versus conditioning pulse potential. $O$, control aCSF; 1 mM 4-AP. Note that $I_{\mathrm{A}}$ was $50 \%$ inactivated at a holding potential of $-58 \mathrm{mV}$ and almost completely inactivated at $-50 \mathrm{mV}$. Also note that the reduction in $I_{\mathrm{A}}$ amplitude by $4-\mathrm{AP}$ over the entire voltage range. The data in $A$ (part $c$ ) and $B$ (part $c$ ) were well fitted to a Boltzmann equation (smoth curves) (see Eq. 1). All currents shown here and in Figure 6 are averages of eight trials. Different cells in $A$ and $B$.

potential can be easily seen. Note the complete block of the $I_{\mathrm{A}}$ available at $-58 \mathrm{mV}$ by $30 \mu \mathrm{M}$ 4-AP. $I_{\mathrm{A}}$ inactivation curves in control aCSF and $300 \mu \mathrm{M}$ adenosine are shown in Figure $6 D$. In this cell, adenosine $(300 \mu \mathrm{M})$ shifted the inactivation curve in the depolarizing direction by about $5 \mathrm{mV}$. This effect reversed upon washout. The effect of adenosine on the inactivation characteristics of $I_{\mathrm{A}}$ at threshold in LC neurons was examined by calculating the shift in the inactivation curve at $80 \%$ inactivation, which occurs at a potential near threshold in LC neurons (see above). The mean depolarizing shift induced by adenosine $(300 \mu \mathrm{M})$ was $4.6 \pm 0.6 \mathrm{mV}(n=5)$. Due to the steepness of the steady-state inactivation curve, at the resting membrane potential, an average of 2.5 times more A-current was available for activation in the presence of adenosine than in control conditions at threshold.
In five cells, we determined the effect of adenosine on $I_{\max }$, $\mathrm{V}_{\mathrm{h}}$, and $K$, the three parameters describing the best-fitted Boltzmann curve for the data obtained from the steady-state inactivation protocol (see Eq. 1 above). The mean values of these parameters under control conditions were $I_{\max }=0.22 \pm 0.02$ $\mathrm{nA}, V_{h}-60.4 \pm 1.2 \mathrm{mV}$, and $K=3.1 \pm 0.4$, and in the presence of $300 \mu \mathrm{M}$ adenosine were $I_{\max }=0.23 \pm 0.02 \mathrm{nA}, V_{h}=-56.7$ $\pm 1.1 \mathrm{mV}$, and $K 3.8 \pm 0.4$. Inactivation curve data were analyzed with a MANOVA. The adenosine-induced alteration of $V_{h}$ was statistically significant (univariate $F=32.35, p=0.005$, $\alpha=0.017)$. There was no statistically significant effect of adenosine on either $I_{\max }(p=0.706)$ or $K(p=0.044)$. These data indicate that the primary action of adenosine upon $I_{\mathrm{A}}$ is to shift the voltage dependence of steady-state inactivation in the depolarizing direction. 
A
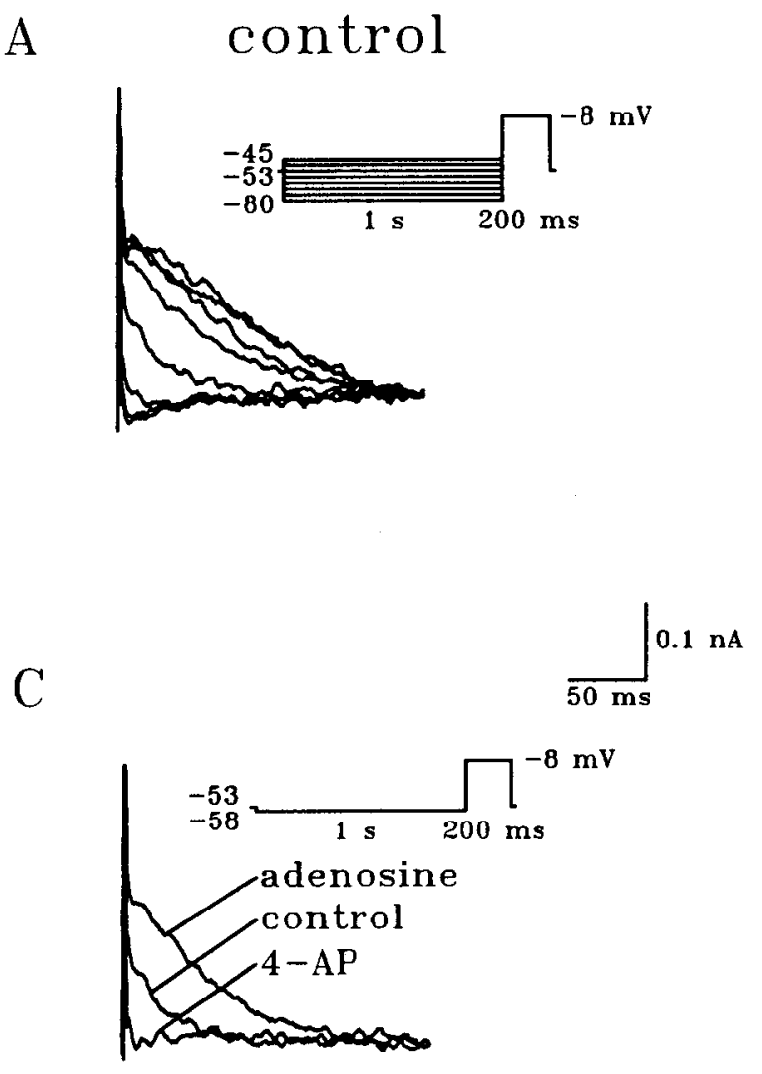

$\mathrm{B}$

adenosine

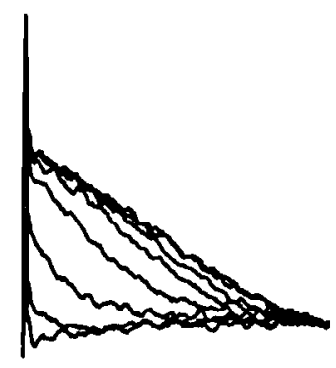

$\mathrm{D}$

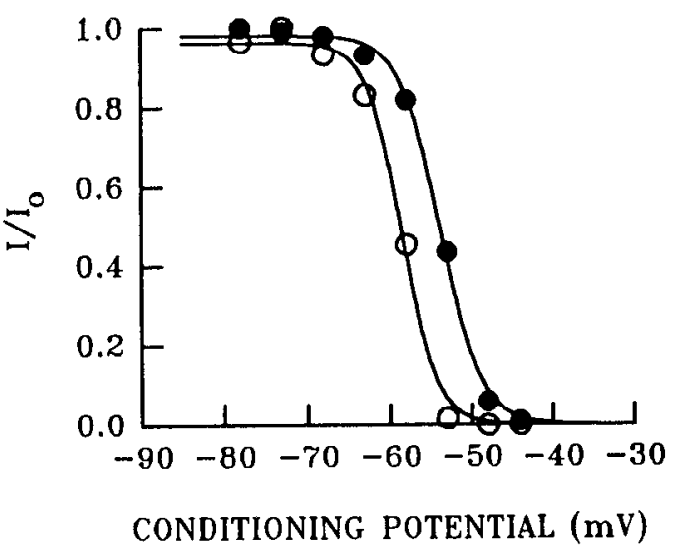

Figure 6. Adenosine modulation of $I_{\mathrm{A}}$ inactivation in a typical LC neuron. All currents shown are from the same cell. $A$, Currents elicited with the steady-state inactivation protocol in control aCSF (see inset). $B$, Addition of $300 \mu \mathrm{M}$ adenosine resulted in an enhancement of $I_{\mathrm{A}}$ current elicited with the same protocol. This effect was most prominent for the smaller currents, that is, those evoked by the four most depolarized conditioning pulses. $C$, Overlay of A-currents. $I_{\mathrm{A}}$ recorded in control aCSF, in the presence of $300 \mu \mathrm{M}$ adenosine, and in $30 \mu \mathrm{M} 4$-AP elicited with depolarization from a conditioning pulse of $-58 \mathrm{mV}$, which is just below threshold. Note that adenosine caused a greater than twofold increase in $I_{A}$, whereas $30 \mu \mathrm{M} 4-\mathrm{AP}$ is sufficient to block all the available $I_{\mathrm{A}}$ at this potential. $D$, Plot of the normalized peak amplitude of $I_{\mathrm{A}}$ as a function of the conditioning pulse potential. $\mathrm{O}$, control aCSF; $\bullet, 300 \mu \mathrm{M}$ adenosine. Adenosine shifted the steady-state inactivation curve in the depolarizing direction by 4.8 $\mathrm{mV}$. This effect reversed upon washout.

\section{Discussion}

The present study demonstrates that adenosine decreases the duration of action potentials in LC neurons by modulating the voltage dependence of $I_{\mathrm{A}}$ inactivation. This is a previously unreported action of adenosine. The adenosine-induced decrease in action potential duration of LC neurons is receptor mediated, as it is concentration dependent and is antagonized by the adenosine receptor antagonist 8 -SPT. We have previously shown that adenosine hyperpolarizes LC neurons (Shefner and Chiu, 1986). This adenosine-activated hyperpolarization is blocked by barium (Pan, unpublished observation). The fact that adenosine decreases action potential duration in the absence of any hyperpolarization indicates that the shortening of the action potential is not simply secondary to adenosine-induced membrane hyperpolarization. Furthermore, under voltage-clamp conditions, adenosine enhances $I_{\mathrm{A}}$ in the absence of hyperpolarization. When barium is not present, adenosine-induced hyperpolarization may also contribute to the narrowing of the action potential, as hyperpolarization itself decreases action po- tential duration in LC neurons by removing inactivation of $I_{\mathrm{A}}$ (S. S. Osmanović, unpublished observation).

The adenosine-induced reduction of action potential duration is consistent with previous reports that adenosine shortens action potential duration in cultured dorsal root ganglion ncurons (Dolphin et al., 1986; MacDonald et al., 1986) and in superior cervical ganglion neurons (Henon and McAfee, 1983). In these preparations, however, this action of adenosine was explained by direct inhibition of calcium currents. Adenosine was also found to reduce action potential duration in CA1 neurons in hippocampal slices (Proctor and Dunwiddie, 1983; Halliwell and Scholfield, 1984). Calcium currents in hippocampal neurons were not altered by adenosine and it was concluded that adenosine indirectly reduced calcium entry by activating a potassium conductance in these cells (Halliwell and Scholfield, 1984). Which of these two mechanisms is responsible for adenosine-induced shortening of the action potential may depend on the specific cell type studied (e.g., peripheral vs central neurons) and/or the stage of development (newborn vs adult). The concentrations of adenosine used in the present experiments were based on our 
previous work (Shefner and Chiu, 1986) and were chosen in view of the fact that adenosine uptake and its metabolism by adenosine deaminase were not blocked in our experiments. These concentrations are consistent with the range of concentrations used in the studies cited above.

The present study shows that the adenosine-induced reduction of action potential duration in LC neurons is specifically blocked by 4-AP. 4-AP is not known to block calcium conductances. If the reduction of action potential duration by adenosine is mediated by a direct inhibition of calcium current, then the adenosine-induced reduction in action potential duration should still be seen in the presence of 4-AP. Therefore, it is unlikely that adenosine directly inhibits calcium current in LC neurons; rather, calcium entry during the action potential is probably indirectly inhibited by enhancement of a potassium conductance. The adenosine-induced reduction of action potential duration persists in the presence of the potassium channel blockers barium, cesium, and TEA, which have been shown to block delayed rectifiers, inward rectifiers, and calcium-dependent potassium conductances. It is unlikely, therefore, that these conductances mediate the reduction of action potential duration by adenosine. 4-AP has been shown to block $I_{\mathrm{A}}$ and delayed rectifiers. The blockade of the adenosine-induced decrease in action potential duration by 4-AP cannot be accounted for by an enhancement of the delayed rectifier, as the adenosine effect was still present in barium, cesium, and TEA. $I_{\mathrm{A}}$ is the only potassium conductance blocked by 4-AP that is not blocked by these other agents. It is clear that $I_{\mathrm{A}}$ contributes to the repolarization of the action potential, as administration of 4-AP prolongs the duration and increases the amplitude of the action potential.

The fact that a relatively low concentration of 4-AP $(30 \mu \mathrm{M})$ was sufficient to antagonize the adenosine-induced reduction of action potential duration led us to consider the possibility that $I_{\mathrm{D}}$, a transient outward current with a much longer decay time constant and greater sensitivity to 4-AP block (Storm, 1988), could contribute to the shape of the action potential. When longlasting test pulses $(5-30 \mathrm{sec})$ were used in the standard activation and inactivation protocols, no slowly inactivating component of the transient outward current was found, indicating the absence of $I_{\mathrm{D}}$ in LC neurons.

Previously, 4-AP has been found to antagonize other effects of adenosine in the CNS. The adenosine-induced reduction of firing rate in cerebral cortex was blocked by 4-AP (Perkins and Stone, 1980). In olfactory cortex, aminopyridines were found to be the most effective blockers of adenosine-induced reduction of EPSPs, being more effective than barium, cesium, and TEA (Scholfield and Steel, 1988). 4-AP also blocked the adenosineinduced reduction of EPSPs and field potentials in CA3 region of the hippocampus (Okada and Ozawa, 1980). The adenosineinduced block of afterpotentials that follow antidromic population spikes in CAl hippocampal pyramidal neurons in low calcium medium was also prevented by 4-AP (Schubert and Lee, 1986). These authors suggest the anticonvulsant activity of adenosine could be due to its facilitation of a 4-AP-sensitive current $\left(I_{\mathrm{A}}\right)$.

In the present report, we report that the major effect of adenosine on $I_{\mathrm{A}}$ is to shift the steady-state inactivation curve of $I_{\mathrm{A}}$ in the depolarizing direction without affecting the magnitude of the peak current or the steady-state activation curve of $I_{\mathrm{A}}$. The effect of adenosine on $I_{\mathrm{A}}$ is seen only in the voltage range in which $I_{\mathrm{A}}$ is partially inactivated. It has been previously reported that adenosine did not alter $I_{\mathrm{A}}$ in hippocampal neurons (Greene and IIaas, 1985; Gerber et al., 1989). In these reports, the conditions that were used to evoke $I_{\mathrm{A}}$ closely matched our activation protocol, in which $I_{\mathrm{A}}$ is completely activated. In our activation protocol, the voltage-dependent removal of inactivation is complete, and under these conditions, no action of adenosine on $I_{\mathrm{A}}$ is observed. When an inactivation protocol is used in which $I_{\mathrm{A}}$ is partially inactivated, however, the effect of adenosine can be clearly seen.

The voltage-clamp experiments described above were performed in $20 \mathrm{~mm} \mathrm{Mg}^{2+}$ in order to block inward calcium currents. Magnesium has been shown to cause a depolarizing shift in the voltage dependence of $I_{\mathrm{A}}$ activation and inactivation in sensory neurons (Mayer and Sugiyama, 1988). Therefore, the position of activation and inactivation curves for $I_{\mathrm{A}}$ in LC neurons under physiological conditions would be expected to be in a more hyperpolarized potential range than in our voltage-clamp experiments. The presence of magnesium would not affect our interpretation of the effect of adenosine on the inactivation properties of $I_{\mathrm{A}}$, however, as magnesium was present both in control and after the application of adenosine.

In our voltage-clamp experiments the steady-state conductance was $4.7 \pm 0.5 \mathrm{nS}$ in control and $5.3 \pm 0.6 \mathrm{nS}$ in adenosine (300 $\mu \mathrm{M}, n=5$ ). A small adenosine-induced increase in conductance should not shift the position of the steady-state inactivation curve for $I_{\mathrm{A}}$ on the voltage axis. In addition, our data indicate that the peak amplitude of $I_{\mathrm{A}}$ was unchanged by adenosine. For these reasons, a small adenosine-induced change in the steady-state conductance would not change our interpretation of adenosine's effect on the voltage dependence of inactivation of $I_{\mathrm{A}}$.

In our current-clamp experiments, it was noted that $30 \mu \mathrm{M}$ 4-AP could block the adenosine-induced decrease in the duration of spontaneous action potentials. This finding is consistent with our voltage-clamp experiments indicating that $30 \mu \mathrm{M} 4-\mathrm{AP}$ could block all of the $I_{\mathrm{A}}$ evoked from the resting potential $(-58$ $\mathrm{mV}$ ), a condition under which $I_{\mathrm{A}}$ is partially inactivated (see Fig. $6 C$ ). Higher concentrations of 4-AP (1 mM) were needed to block $I_{\mathrm{A}}$ fully under conditions in which $I_{\mathrm{A}}$ can be maximally activated, as in our standard activation protocol. Schubert and Lee (1986) have previously shown that adenosinc suppresses the repetitive firing that follows population spikes in hippocampal CAl neurons, and that 4-AP antagonized this action of adenosine at a concentration of only $50 \mu \mathrm{M}$, whereas $5 \mathrm{mM}$ TEA did not block this action of adenosine at all. These concentrations of 4-AP and TEA correspond closely to the concentrations of 4-AP and TEA used in the present study.

The action of adenosine described in this article resembles the effect of $\mathrm{GABA}_{\mathrm{B}}$ receptor modulation of $I_{\mathrm{A}}$ in cultured CA1 hippocampal neurons (Saint et al., 1990). As adenosine receptors have been shown to converge upon the same second messenger pathways as $\mathrm{GABA}_{\mathrm{B}}$ and $5 \mathrm{HT}_{1 \mathrm{~A}}$ receptors (Andrade et al., 1986; McCormick and Williamson, 1989), it is possible that modulation of $I_{\mathrm{A}}$ may also be a convergent pathway for the action of these neurotransmitters. In addition, activation of GA$\mathrm{BA}_{\mathrm{B}}$ receptors, like activation of adenosine receptors, has also been shown to reduce release of norepinephrine from norad. renergic nerve terminals (Bowery et al., 1980). One possible mechanism for reducing neurotransmitter release is to reduce calcium influx at the nerve terminal. Enhancement of $I_{\mathrm{A}}$ decreases action potential duration and could thereby reduce calcium influx and neurotransmitter release at the nerve terminal (Shimahara, 1983). The adenosine-induced reduction of the ac- 
tion potential through the enhancement of $I_{\mathrm{A}}$ could be a mechanism by which adenosine reduces the release of norepinephrine from noradrenergic terminals.

\section{References}

Andrade R, Malenka RC, Nicoll RA (1986) A G protein couples serotonin and $\mathrm{GABA}_{\mathrm{B}}$ receptors to the same channels in hippocampus. Science 234:1261-1265.

Bean BP (1989) Classes of calcium channels in vertebrate cells. Annu Rev Physiol 51:367-384.

Bowery NG, Hill DR, Hudson AL, Doble A, Middlemiss J, Turnbull M (1980) (-)Baclofen decreases neurotransmitter release in the mammalian CNS by action at a novel GABA receptor. Nature 283: 92-94.

Bruns RF, Lu GH, Pugsley TA (1986) Characterization of the $A_{2}$ adenosine receptor labeled by $\left[{ }^{3} \mathrm{H}\right] \mathrm{NECA}$ in rat striatal membranes. Mol Pharmacol 29:331-346.

Clanachan AS, Johns A, Paton DM (1977) Presynaptic inhibitory actions of adenine nucleotides and adenosine on neurotransmission in the rat vas deferens. Neuroscience 2:597-602.

Dolphin AC, Forda SR, Scott RH (1986) Calcium-dependent currents in cultured rat dorsal root ganglion neurones are inhibited by an adenosine analogue. J Physiol (Lond) 373:47-61.

Dunwiddie TV (1985) The physiological role of adenosine in the central nervous system. Int Rev Neurobiol 27:63-139.

Dunwiddie TV, Worth TS, Olsson RA (1986) Adenosine analogs mediating depressant effects on synaptic transmission in rat hippocampus: structure-activity relationships for the $\mathrm{N}^{6}$ subregion. Naunyn Schmiedebergs Arch Pharmacol 334:77-85.

Ebstein RP, Daly JW (1982) Release of norepinephrine and dopamine from brain vesicular preparations: effects of adenosine analogues. Cell Mol Neurobiol 2:193-204.

Foote SL, Bloom FE, Aston-Jones G (1983) Nucleus locus ceruleus: new evidence for anatomical and physiological specificity. Physiol Rev 63:844-914.

Fredholm BB (1976) Release of adenosine-like material from isolated perfused dog adipose tissue following sympathetic nerve stimulation and its inhibition by adrenergic $\alpha$-receptor blockade. Acta Physiol Scand 96:422-430.

Gerber U, Greene RW, Haas HL, Stevens DR (1989) Characterization of inhibition mediated by adenosine in the hippocampus of the rat in vitro. J Physiol (Lond) 417:567-578.

Greene RW, Haas HL (1985) Adenosine actions on CAl pyramidal neurones in rat hippocampal slices. J Physiol (Lond) 366:119-127.

Greene RW, Haas HL (1991) The electrophysiology of adenosine in the central nervous system. Prog Neurobiol 36:329-341.

Gustafsson LE (1984) Adenosine antagonism and related effects of theophylline derivatives in guinea pig ileum longitudinal muscle. Acta Physiol Scand 122:191-198.

Halliwell JV, Scholfield CN (1984) Somatically recorded Ca-currents in guinea-pig hippocampal and olfactory cortex neurones are resistant to adenosine action. Neurosci Lett 50:13-18.

Harms HH, Wardeh G, Mulder AH (1978) Adenosine modulates depolarization-induced release of ${ }^{3} \mathrm{H}$-noradrenaline from slices of rat brain neocortex. Eur J Pharmacol 49:305-308.

Henon BK, McAfee DA (1983) The ionic basis of adenosine receptor actions on post-ganglionic neurones in the rat. J Physiol (Lond) 336: 607-620.

MacDonald RL, Skerritt JH, Weř MA (1986) Adenosine agonists reduce voltage-dependent calcium conductance of mouse sensory neurones in cell culture. J Physiol (Lond) 370:75-90.

Mayer ML, Sugiyama K (1988) A modulatory action of divalent cations on transient outward current in cultured rat sensory neurones. $\mathrm{J}$ Physiol (Lond) 396:417-433.

McCormick DA, Williamson A (1989) Convergence and divergence of neurotransmitter action in human cortex. Proc Natl Acad Sci USA 86:8098-8102.

Miller RG (1981) Simultaneous statistical inference. New York: Springer.

Okada Y, Ozawa S (1980) Inhibitory action of adenosine on synaptic transmission in the hippocampus of the guinea pig in vitro. Fur $\mathbf{J}$ Pharmacol 68:483-492.

Olpe HR, Jones RSG, Steinmann MW (1983) The locus coeruleus: actions of psychoactive drugs. Experientia 39:242-249.

Osmanović SS, Shefner SA (1993) Calcium-activated hyperpolarizations in rat locus coeruleus neurons in vitro. J Physiol (Lond) 469: 89-109.

Pan WJ, Shefner SA (1992) Adenosine modulates a transient outward current in rat locus coeruleus neurons. Soc Neurosci Abstr 18:1341.

Pan WJ, Osmanovic SS, Shefner SA (1988) Adenosine increases $\mathrm{K}^{+}$ conductance in rat locus coeruleus neurons. Soc Neurosci Abstr 14: 278.

Perkins MN, Stone TW (1980) 4-Aminopyridine blockade of neuronal depressant responses to adenosine triphosphate. Br J Pharmacol 70 : $425-428$

Proctor WR, Dunwiddie TV (1983) Adenosine inhibits calcium spikes in hippocampal pyramidal neurons in vitro. Neurosci Lett 35:197201.

Rudy B (1988) Diversity and ubiquity of K channels. Neuroscience $25: 729-749$

Saint DA, Thomas T, Gage PW (1990) GABA agonists modulate a transient potassium current in cultured mammalian hippocampal neurons. Neurosci Lett 118:9-13.

Scholfield CN, Steel L (1988) Presynaptic K-channel blockade counteracts the depressant effect of adenosine in olfactory cortex. Neuroscience 24:81-91.

Schubert P, Lee KS (1986) Non-synaptic modulation of repetitive firing by adenosine is antagonized by 4-aminopyridine in a rat hippocampal slice. Neurosci Lett 67:334-338.

Shefner SA, Chiu TH (1986) Adenosine inhibits locus coeruleus neurons: an intracellular study in a rat brain slice preparation. Brain Res 366:364-368.

Shimahara T (1983) Presynaptic modulation of transmitter release by the early outward potassium current in Aplysia. Brain Res 263:5156.

Storm JF (1988) Temporal integration by a slowly inactivating $\mathrm{K}^{+}$ current in hippocampal neurones. Nature 336:379-381.

Sturgill l'W, Schrier MBK, Gilman AG (1975) Stimulation of cyclic AMP accumulation by 2-chloroadenosine: lack of incorporation of nucleoside into cyclic nucleotides. J Cyclic Nucleotide Res 1:21-30.

Verhaeghe RH, Vanhoutte PM, Shepard JT (1976) Inhibition of sympathetic neurotransmission in canine blood vessels by adenosine and adenine nucleotides. Circ Res 40:208-215.

Waldeck B (1971) Some effects of caffeine and aminophylline on the turnover of catecholamines in the brain. J Pharm Pharmacol 23:824830 .

Williams JT, North RA, Shefner SA, Nishi S, Egan TM (1984) Membrane properties of rat locus coeruleus neurons. Neuroscience 13:137156. 